\title{
Determinants and Impact of Artificial Intelligence on Organizational Competitiveness: A Study of Listed American Companies
}

\author{
Chinwe Chinonso Iwuanyanwu \\ Department of Computer and Information Systems, School of Informatics, Humanities and Social Sciences, Robert Morris \\ University, Moon Township, PA, USA \\ Email: chinweiwuanyanwu@yahoo.com
}

How to cite this paper: Iwuanyanwu, C. C. (2021). Determinants and Impact of Artificial Intelligence on Organizational Competitiveness: A Study of Listed American Companies. Journal of Service Science and Management, 14, 502-529.

https://doi.org/10.4236/jssm.2021.145032

Received: July 26, 2021

Accepted: October 16, 2021

Published: October 19, 2021

Copyright $\odot 2021$ by author(s) and Scientific Research Publishing Inc. This work is licensed under the Creative Commons Attribution International License (CC BY 4.0).

http://creativecommons.org/licenses/by/4.0/

(c) (i) Open Access

\begin{abstract}
This study investigated the institutional factors affecting the application of Artificial Intelligence (AI) by American companies. The objectives of the study were to: 1) determine the institutional factors affecting AI; 2) evaluate the impact of institutional factors on application level of AI; and 3) assess the impact of AI on organizational competitiveness. This study adopted a survey research design. The population of the study is comprised of all publicly quoted companies on NASDAQ (National Association of Securities Dealers Automated Quotations). Data collection was aided by structured questionnaire. In line with the $10 \%$ rule of thumb for large population size, $330 \mathrm{com}$ panies were taken as the sample size for the study. The 330 companies were randomly selected, and a copy of questionnaire dispatched to each company, making a total of 330 copies of questionnaire administered. Result shows that the relatively high-ranking institutional factors affecting AI application are Competitors' activities, Consultants/Professional bodies, actions of Multinational organizations, and the need to satisfy customers. A thematic analysis of the high-ranking factor shows that the mimetic factors (i.e., competitors' activities and actions of multinational organizations) are the strongest factors driving the application of AI by the companies. The normative factor (i.e., recommendations of consultants/professional bodies/experts) also has appreciable influence on AI application. Result also shows that institutional factors jointly account for an appreciable level of AI application in American companies. Result suggests that the application of AI has a significantly positive impact on organizational competitiveness. This makes it compelling to encourage investment in AI given its significantly positive impact on organizational competitiveness. The study contributes to knowledge by providing em-
\end{abstract}


pirical evidence on the institutional factors affecting AI in American companies. This study is also one of the earliest empirical studies on the deployment of AI by listed companies in the U.S. The study therefore contributes to the burgeoning literature on AI. The study provides empirical evidence on the applicability of the theory of institutional isomorphism to the adoption of technological innovation.

\section{Keywords}

American Companies, Artificial Intelligence, Institutional Factors, Institutional Isomorphism, Organizational Competitiveness, NASDAQ

\section{Introduction}

The concept of Artificial Intelligence (AI) has been gaining huge traction in recent times. The ongoing COVID-19 pandemic is imposing constraint on organizations to come up with innovative ways of operating, whilst satisfying the requirements of self-isolation and social distancing. This implies that operations requiring physical human intervention have to be automated, and $\mathrm{AI}$ is an innovation leading the way in this direction (Werner \& Gehrke, 2015). In other words, machine would have to be relied upon to take over human interaction as supported by the concept of AI.

The variety, volume and velocity of data generated on a daily basis through the use of electronic device also imply that machines would have to be relied upon to take inputs, process transactions and generate output for goods and services (Sumbal, Tsui, \& See-to, 2017). This development again reiterates the growing importance of AI. Artificial intelligence (AI) refers to the simulation of human intelligence in machines that are programmed to think like humans and mimic their actions. The term may also be applied to any machine that exhibits traits associated with a human mind such as learning and problem-solving. Artificial intelligence has the ability of a computer or computer-controlled robot to perform tasks commonly associated with intelligent beings (Zhou, Fu, \& Yang, 2016).

Whilst it is acknowledged that $\mathrm{AI}$ is one of the emerging and disruptive technologies, little is known as to the factors promoting the adoption of AI in organizations. Organizations are open systems in the sense that they influence the society and are also influenced by the society (Navickas \& Gružauskas, 2016). In other words, they interact with the society. This implies that various stakeholders influence the organization as an open system. Not surprisingly therefore, various stakeholder groups affecting the operations of an organization have been identified in literature, including but not limited to owners/shareholders, suppliers, government, financers, employees, trade unions, customers, competitors, investors, host community and consultants, among others. Studies have shown that these stakeholders affect the activities of an organization (e.g. McRobert, 
Hill, Smale, Hay, \& Van der Windt, 2018). Whilst studies have investigated stakeholder influence on various issues and the adoption of innovation, little is known as to the impact of stakeholder actions on the adoption of AI. Such knowledge is important in contributing to the debate on the drivers of $\mathrm{AI}$ as an innovation. Knowledge on the institutional determinants of AI can promote the uptake and diffusion rate of $\mathrm{AI}$ as a technological innovation (Bondarouk \& Brewster, 2016). It is important to drive AI in a post COVID-19 era considering the criticality of technological innovation in the recoveries and restarting of the world economy.

Against this backdrop, the objectives of the current study are to: 1) determine the Institutional factors affecting AI; 2) evaluate the impact of institutional factors on application level of AI; and 3) assess the impact of AI on organizational competitiveness. The study focused on listed American companies. The U.S represents an important context for the current study because of its economic and political power in the world. The drivers of AI adoption in the U.S. may reflect the determinants of AI application in other developed countries of the world. A study from the U.S is also important considering that it is one of the worst hit countries in the world during the peak of the COVID-19 pandemic. Thus, technological innovation such as AI is critical to restarting the world economy, including the US. With the new world order promoting automation at a higher level-in order to satisfy the dictates of social distance, self-isolation and computer-mediated interaction between humans-the upscaling of AI has never been more appropriate.

This study adopted a survey research design. The population of the study is comprised of all publicly quoted companies on NASDAQ (National Association of Securities Dealers Automated Quotations). Data collection was aided by structured questionnaire. In line with the $10 \%$ rule of thumb for large population size (Alreck \& Settle, 1995), 330 companies were taken as the sample size for the study. The 330 companies were randomly selected, and a copy of questionnaire dispatched to each company, making a total of 330 copies of questionnaire administered. Result shows that mimetic factors (i.e., competitors' activities and actions of multinational organizations) are the strongest factors driving the application of AI by the companies. The normative factor (i.e., recommendations of consultants/professional bodies/experts) also has appreciable influence on AI application. The only coercive factor that recorded a relatively high impact is the need to satisfy customers. Overall, institutional isomorphic factors affect the application of AI by American companies. However, the level of influence exerted by the institutional factors is generally Moderate (research objective one). Whilst the factors significantly driving the application of AI are Government regulations, financial institutions/Fund Providers and Company's customers, the need to satisfy customers has the strongest positive impact on AI application. Result also shows that the application of AI has a significant positive impact on organizational competitiveness (research objective three). This study contributes to 
knowledge by providing empirical evidence on the institutional factors affecting AI in American companies. This study is also one of the earliest empirical studies on the deployment of AI by listed companies in the U.S. the study therefore contributes to the burgeoning literature on AI. The study provides empirical evidence on the applicability of the theory of institutional isomorphism to the adoption of technological innovation. The current study is timely and significant in the light of recent developments in the information technology sector promoting disruptive technologies as a means of surviving competition in the unpredictable business environment. The relevance of the study also consists in the high utilization rate of information technology in recent times due to the COVID-19 pandemic in which a number of human activities have gone virtual in a bid to comply with social distancing requirement and self-isolation as a means of checkmating the spread of COVID-19.

The remainder of the paper is organized into four sections (Section 2 to 5). Section 2 covers literature review, while Section 3 explains the methodology adopted for the study. Section 4 presents result and analysis. The paper is concluded in Section 5.

\section{Literature Review}

\subsection{Institutional Factors Affecting the Deployment of Artificial Intelligence}

According to the theory of institutional isomorphism, institutional factors affect the adoption of an innovation. Developed by sociologists and organizational theorists (Ahl, 1999), isomorphism explains the process by which organizations conform to their external environment. The theory explains the factors which may force companies to comply with the adoption of AI as an innovation. DiMaggio and Powell (1983: p. 149), explains isomorphism as 'a constraining process that forces one unit in a population to resemble other units that face the same set of environmental conditions. In other words, the institutional theory explains the similarity in the level of application of AI. The institutional theory identifies three major factors affecting the adoption of an innovation, namely: coercive isomorphism, mimetic isomorphism and normative isomorphism. As the name suggests, coercive isomorphism are factors that coerce or force an organization to resemble another organization (Oyewo, Ajibolade, \& Obazee, 2019). The coercive pressures are normally exerted by organizations of stakeholder groups that have a high level of influence on an organization. These may emanate from owners/shareholders, parent companies (for subsidiaries of multinational organizations), associates (for companies belonging to the same group), government, regulatory authorities, financiers/fund providers, and customers (assuming such customers have higher bargaining power or account for a major component of sales/turnover or income of the business).

Mimetic isomorphism results from a process of one organization emulating or imitating other organizations in terms of mode of operation, internal 
structures, organizational and procedures. The imitating organization will typically regard the imitated organization as a model or highly-successful organization. In essence, the imitated organization has recorded a level of success or achievement which causes the imitating organization to model its activities, procedures and operations around the seemingly or supposedly successful organization (Cuganesan, Dunford, \& Palmer, 2012). Normative isomorphism occurs when organizations follow the recommendations of professionals, experts or highly knowledgeable individuals or organizations in adopting a practice, structure or procedure. Normative isomorphism usually arises from the knowledge advocated by particular dominant professions, professional bodies and/or consultants (Cinquini \& Tenucci, 2010).

These three isomorphic factors may affect the adoption of AI given its nascent and emerging nature (Appelbaum, Kogan, \& Vasarhelyi, 2017). The contextualization of the isomorphism theory to this study implies that the adoption of AI may be shaped by a combination of formal and informal pressures exerted on organizations by other companies/institutions that they look up to an depend on for guidance (coercive isomorphism), emulation of technological innovation and practice of other organizations regarded as being highly successful (mimetic isomorphism), and recommendations on by researchers, experts, professional bodies and consultants on the performance implications and benefits of AI (normative isomorphism).

In other words, the domestication of the theory of institutional isomorphism may suggests that coercive isomorphic factors such as Government regulations, demands and expectations of owners/shareholders for company to improve competitiveness through deployment of technological innovation, pressure exerted by financial institutions/Fund Providers and the need to better satisfy customer through the deployment of emerging technology may force companies to adopt AI (Baron, Mustafa, \& Agustina, 2018). Furthermore, mimetic isomorphic factors such as Competitors' activities and evidence on the deployment of AI by renown and blue-chip companies may also drive AI adoption. On a final note, research and recommendations of Consultants/Professional bodies on Information technology may further motivate companies to adopt AI as an innovation. Studies have shown that institutional factors affect the adoption of innovation (e.g. Bondarouk \& Brewster, 2016; Guido, Pichierri, Rizzo, Chieffi, \& Moschis, 2020).

\subsection{Benefits of Artificial Intelligence Deployment}

The automation of the processes in organisations implies the application of information technology to all or most activities of the organisation. Therefore, the application of AI to business operations may enhance organisational performance and create competitive advantage. Studies have shown that information technology has strategic ramifications and can contribute to the achievement of organisational objectives (e.g., McRobert, Hill, Smale, Hay, \& Van der Windt, 
2018).

Organisational performance refers to how well an entity is achieving its specified goals using the resources available at its disposal. It is important to measure performance on a regular basis to know how well predetermined objectives are achieved (Mohammadpoor \& Torabi, 2019). One of the veritable ways an organisation can track its performance over time is the development of Key performance indicators (KPIs). Key performance indicators assist organisations to ensure that objectives are specific, measurable, achievable, relevant to the mission of the organisational, and timely (SMART). Although objectives are conventionally measured in financial terms, there is an increasing awareness on the need to focus on non-financial performance indicators. One of the prominent frameworks on performance measures that de-emphasizes the excessive focus on financial performance is the balanced score card. The balanced score card as the name connotes emphasizes three non-financial performance perspectives (customer, internal business process, and product development/learning \& growth) whilst not discountenancing the importance of the financial perspective (Navickas \& Gružauskas, 2016). The balanced scorecard therefore has four perspectives of customer, internal business process, product development/learning \& growth, and financial. However, the non-financial perspectives are considered more important than the financial perspective because they determine the extent of economic/financial success of an organisation. The perspectives are briefly explained as follows:

1) Customer perspective focuses on how well a company is satisfying its customers. This can be indicated using key performance metrics such as: number of new customers, number of existing customers, rating from customer satisfaction surveys, market share, changes in percentage of customer patronage.

2) Internal business process focuses on the efficiency of business operations and the quickness in the input-output process. It gauges how quickly or slowly an organisation executes activities internally (between departments/strategic business units within the organisation) or externally (between the organisation and external third parties e.g., customers).

3) Product development/Learning and growth is the perspective that gauges the ability of an organisation to develop new products or modify existing products to meet the changing tastes and needs of customers. This perspective also assesses the organisation's ability to apply new knowledge/learning to develop new products.

4) Financial perspective focuses on the financial performance of an organisation in terms of its ability to manage cost, make profit, generate returns for stakeholders, and maximise shareholders' value. Financial performances are usually communicated through the issuance of audited annual reports and analysis of such financial statements using accounting ratios such as profitability, liquidity, management efficiency, long-term stability and solvency, and investment ratios. 
It becomes important for organisations deploying AI to assess performance from these four dimensions as this will justify the value relevance of switching from a manual method to an automated system driven by AI. AI applications can be deployed on hand-held device and accessible on mobile devices and desktop applications (Rasmussen \& Ulrich, 2015). The application is expected to improve customer patronage and satisfaction (customer perspective) because the application will have a customer interface where customers can log in to monitor the status of their on-going job, make enquiries, update their requests, exchange correspondences, lodge their complaints and even rate the services of the company. This arrangement is expected to enhance a two-way and robust communication system. AI software can also provide valuable opportunity for the company to maintain a robust database of customers which can be useful for amassing big data and performing business analytics to improve service delivery (Searle, 2006; Spenner \& Freeman, 2012).

The automation of operations in organisations using $\mathrm{AI}$ is expected to enhance the internal business processes (internal business process perspective). The automation of key activities such as employee management, aircraft management and job management are aimed at improving the turnaround time of intra-organisation (task interdependence among strategic business units/departments e.g., human resource departments, operations, customer service, marketing/business development, IT, internal control, accounts and finance) and inter-organisational activities (i.e., relationship between the organisation and its customers or other third parties). Automation of operations in organisations, including the accounting processes and invoice management contributes to proper record keeping, reliability of costing jobs, proper pricing and timeliness of rendering accounting reports (Steenbruggen, Tranos, \& Nijkamp, 2015).

Automation is also expected to reduce operating cost in the long run (financial perspective). Automation may reduce the number of employees needed to work because non-core activities that have erstwhile been carried out using human intervention can be eliminated, as the organisation concentrates on core activities. Automation also improves efficiency by reducing the time required to complete tasks which reduces labour costs and associated overheads. The learning effect brought about by automation also has the potential of reducing wastage and inefficiency in the process. This produces cost saving and improves the profitability of the organization (Stuart \& Norvig, 2016). If organizations extensively deploying AI are able to achieve improved performance in the four performance dimensions as proposed by the balanced scorecard above competitors, it will be able to attract more customers and investors, which gives such companies competitive advantage. However, a company extensively deploying AI may be able to sustain its competitive advantage (i.e. Sustainable Competitive Advantage) if it maximises the benefits from the software. Meanwhile, sustainable competitive advantage is the ability of an organisation to consistently improve and maintain an above-industry/sector-average performance not only in the 
short- to medium-term but also in the long-term (Sumbal, Tsui, \& See-to, 2017). Post completion audit may be one of the strategies to deploy to reinvigorate the effectiveness of AI overtime in the light of changing business environment. Such post completion audit can help ensure that the competitive advantaged gained by automating the processes can be sustained in the long term in the foreseeable future. In sum, the extensively application of AI is expected to improve organisational competitiveness.

\section{Methodology}

\subsection{Research Design and Data Collection Method}

This study adopted a survey research design. Survey research design was selected because it affords the researcher the opportunity to gather quantitative data conveniently and economically from large number of respondents (Saunders, Lewis, \& Thornhill, 2007). Data collection was also aided using questionnaire, because questionnaire is a data collection technique associated with survey research design. The questionnaire was designed in such a manner that it elicited responses on respondent's profile, the application of AI, areas of application of $\mathrm{AI}$, as well as the institutional factors affecting the deployment of AI technologies. The questionnaire also covered innovation attributes affecting AI and competitive advantage. A sample of the questionnaire is presented in Appendix 3.

\subsection{Population and Sample Selection}

The population of the study is comprised of all publicly quoted companies on NASDAQ (National Association of Securities Dealers Automated Quotations). The NASDAQ is an electronic stock exchange with more than 3300 company listings. It currently has a greater trading volume than any other U.S. stock exchange, carrying out approximately 1.8 billion trades per day. The choice of NASDAQ was informed by the consideration that it is the second largest stock exchanges in the US, after NYSE (the New York stock Exchange). The NASDAQ trades shares in a variety of companies, but is well known for being a high-tech exchange, trading many new, high growth, and volatile stocks. Furthermore, the NASDAQ resonates well with the subject of the research on IT considering that it is an electronic exchange, with no physical trading floor, which conducts all its trades through a computer and telecommunications system. In line with the 10\% rule of thumb for large population size (Alreck \& Settle, 1995), 330 companies were taken as the sample size for the study. The 330 companies were randomly selected from companies operating in the information technology sector as they have higher tendency of applying AI as a result of the high level of automation expected from such companies. A copy of questionnaire dispatched to each company, making a total of 330 copies of questionnaire administered. The questionnaire was accompanied by a cover letter, addressed to senior IT personnel to complete on behalf of their companies as they are expected to be sufficiently 
knowledgeable about the IT operations in their organizations.

\subsection{Reliability}

The Cronbach alpha was used to assess reliability/internal consistency. The result of the test is reported in Table 1 .

From the result in Table 1, all items have a Cronbach alpha above the 0.7 recommended minimum to gauge internal consistency. Based on this result, it is concluded that internal consistency is not an issue (Drost, 2011). Full descriptive result containing the frequency distribution of items is presented in Appendix 1 and 2.

\subsection{Validity}

Validity was ensured by adapting measurements in literature to measure variables. The questionnaire was submitted to two experts-one academic well versed in business information technology research, and another business practitioner in a top IT firm-for critiquing. The feedbacks obtained were used to improve the questionnaire. The revised version was subsequently administered. In addition, factor analysis was employed to assess divergent validity as reported in Tables 2(a)-4(c) as follows.

\subsubsection{Validity on Level of Application of Artificial Intelligence}

The significant $\mathrm{p}$ value of 0.000 in Table 2(a) confirms the factorability of AI application level as a variable. The table of communalities (Table 2(b)) shows that the various dimensions of AI application have high degree of extraction, as the item with the least extraction is 0.558 (or 55.8\%) while the highest is 0.794 (79.4\%). The total number of variances explained stood at $69.342 \%$ (Table 2(c)). In Table 2(d), all items loaded strongly in component 1 well above the 0.30 threshold for a reasonable factor analysis, implying that the various dimensions of AI are appreciably applied by American companies. Taken together, the result shows that AI application level was validly measured.

\subsubsection{Validity on Institutional Factors Influencing Deployment of Artificial Intelligence Technologies}

The significant $p$ value of 0.000 in Table 3 (a) confirms the factorability of institutional factors influencing deployment of artificial intelligence technologies. The table of communalities (Table 3(b)) shows that the various institutional factors affecting AI application have high degree of extraction, as the item with

Table 1. Reliability test results.

\begin{tabular}{lcc}
\hline \multicolumn{1}{c}{ Variable } & No. of items & Cronbach Alpha \\
\hline Application of Artificial Intelligence & 6 & 0.811 \\
$\begin{array}{l}\text { Institutional Factors Influencing Deployment of } \\
\text { Artificial Intelligence Technologies }\end{array}$ & 7 & 0.779 \\
Competitive Advantage & 5 & 0.837 \\
\hline
\end{tabular}


Table 2. (a) KMO and Bartlett's Test; (b) Communalities; (c) Total Variance Explained; (d) Component Matrixa.

(a)

\begin{tabular}{lcc}
\hline Kaiser-Meyer-Olkin Measure of Sampling Adequacy. & 0.819 \\
& Approx. Chi-Square & 520.580 \\
Bartlett's Test of Sphericity & df & 15 \\
& Sig. & 0.000 \\
\hline
\end{tabular}

(b)

\begin{tabular}{|c|c|c|}
\hline & Initial & Extractio n \\
\hline The use of technologies that can master human intelligence in a short time & 1.000 & 0.794 \\
\hline The application of technologies that imitate human cognition & 1.000 & 0.728 \\
\hline $\begin{array}{l}\text { The deployment of technologies that automate repetitive and time-consuming } \\
\text { activities }\end{array}$ & 1.000 & 0.623 \\
\hline $\begin{array}{l}\text { The use of technologies that analyze data in ways that human beings may } \\
\text { sometimes not be able to }\end{array}$ & 1.000 & 0.731 \\
\hline The deployment of technologies that detect patterns and make predictions & 1.000 & 0.726 \\
\hline The application of technologies that simulate human consciousness & 1.000 & 0.558 \\
\hline
\end{tabular}

Extraction Method: Principal Component Analysis.

(c)

\begin{tabular}{|c|c|c|c|c|c|c|}
\hline \multirow[b]{2}{*}{ Component } & \multicolumn{3}{|c|}{ Initial Eigenvalues } & \multicolumn{3}{|c|}{$\begin{array}{l}\text { Extraction Sums of } \\
\text { Squared Loadings }\end{array}$} \\
\hline & Total & $\begin{array}{c}\% \text { of } \\
\text { Variance }\end{array}$ & $\begin{array}{c}\text { Cumulative } \\
\%\end{array}$ & Total & $\begin{array}{c}\% \text { of } \\
\text { Variance }\end{array}$ & $\begin{array}{c}\text { Cumulative } \\
\%\end{array}$ \\
\hline 1 & 4.161 & 69.342 & 69.342 & \multirow{6}{*}{4.161} & \multirow{6}{*}{69.342} & \multirow{6}{*}{69.342} \\
\hline 2 & 0.799 & 13.321 & 82.663 & & & \\
\hline 3 & 0.367 & 6.109 & 88.772 & & & \\
\hline 4 & 0.309 & 5.149 & 93.921 & & & \\
\hline 5 & 0.211 & 3.519 & 97.441 & & & \\
\hline 6 & 0.154 & 2.559 & 100.000 & & & \\
\hline
\end{tabular}

Extraction Method: Principal Component Analysis.

(d)

Component

1

The use of technologies that can master human intelligence in a short time

0.891

The application of technologies that imitate human cognition

0.853

The deployment of technologies that automate repetitive and time-consuming activities

The use of technologies that analyze data in ways that human beings may sometimes not be able to

The deployment of technologies that detect patterns and make predictions

Extraction Method: Principal Component Analysis. ${ }^{\mathrm{a}} 1$ components extracted. 
Table 3. (a) KMO and Bartlett's Test; (b) Communalities; (c) Total Variance Explained; (d) Component Matrixa.

(a)

\begin{tabular}{lcc}
\hline Kaiser-Meyer-Olkin Measure of Sampling Adequacy. & 0.820 \\
Bartlett's Test of Sphericity & Approx. Chi-Square & 575.071 \\
& df & 21 \\
& Sig. & 0.000 \\
\hline
\end{tabular}

(b)

\begin{tabular}{lcc}
\hline & Initial & Extractio n \\
\hline Government regulations & 1.000 & 0.489 \\
Company's shareholders & 1.000 & 0.611 \\
Financial institutions/Fund Providers & 1.000 & 0.563 \\
Company's customers & 1.000 & 0.643 \\
Competitors' activities & 1.000 & 0.663 \\
Multinational organizations apply AI technologies & 1.000 & 0.827 \\
Recommendations of Consultants/Professional bodies & 1.000 & 0.726 \\
\hline
\end{tabular}

Extraction Method: Principal Component Analysis.

(c)

\begin{tabular}{ccccccc}
\hline \multirow{2}{*}{ Component } & \multicolumn{3}{c}{ Initial Eigenvalues } & \multicolumn{2}{c}{ Extraction Sums of Squared Loadings } \\
\cline { 2 - 6 } & Total & \% of Variance & Cumulative \% & Total & \% of Variance & Cumulative \% \\
\hline 1 & 4.523 & 64.619 & 64.619 & & & \\
2 & 0.849 & 12.126 & 76.744 & & & \\
3 & 0.632 & 9.033 & 85.778 & & & \\
4 & 0.340 & 4.853 & 90.631 & 4.523 & 64.619 & \\
5 & 0.333 & 4.761 & 95.391 & & & \\
6 & 0.186 & 2.660 & 98.052 & & & \\
7 & 0.136 & 1.948 & 100.000 & & \\
\hline
\end{tabular}

Extraction Method: Principal Component Analysis.

(d)

\begin{tabular}{ll}
\hline & Component \\
Government regulations & 1 \\
Company's shareholders & 0.699 \\
Financial institutions/Fund Providers & 0.782 \\
Company's customers & 0.750 \\
Competitors' activities & 0.802 \\
Multinational organizations apply AI technologies & 0.814 \\
Recommendations of Consultants/Professional bodies & 0.909 \\
\hline
\end{tabular}

Extraction Method: Principal Component Analysis. ${ }^{a} 1$ components extracted. 
the least extraction is 0.489 (or $48.9 \%$ ) while the highest is 0.827 (82.7\%). The total number of variances explained stood at $64.619 \%$ (Table 3(c)). In Table 3 (d), all items loaded strongly in component 1 well above the 0.30 threshold for a reasonable factor analysis, implying that the various institutional factors affect AI deployment in American companies. Taken together, the result shows that the listed institutional factors affecting AI application were validly measured.

\subsubsection{Validity on Competitive Advantage}

The significant $p$ value of 0.000 in Table 4(a) confirms the factorability of Competitive Advantage. The table of communalities (Table 4(b)) shows that the various dimensions of competitive advantage have high degree of extraction, as the item with the least extraction is 0.698 (or 69.8\%) while the highest is 0.873 (87.3\%). The total number of variances explained stood at $76.022 \%$ (Table 4 (c)). In Table 4(d), all items loaded strongly in component 1 well above the 0.30 threshold for a reasonable factor analysis, implying that the various dimensions of competitive advantage were validly measured.

\subsection{Method of Data Analysis}

Descriptive statistical techniques such as frequency counts, Mean, and Standard Deviation were used for analysis. Inferential statistical tools used were exploratory factor analysis (principal component analysis extraction method), one sample t-test (using a test value of 3.0 on the 5-point scale) and regression analysis. The cut-off point for factor analysis was 0.30 . Inferences were drawn at $5 \%$ level of significance.

\section{Results and Analysis}

\subsection{Response Rate and Respondents' Profile}

From a total of 330 copies of questionnaire administered, 127 copies were retrieved, 5 copies were not fit for use because of incomplete response to all questionnaire items. The 122 copies found suitable for use were processed for analysis, representing an effective response rate of $37.0 \%$. This proportion is considered adequate to perform statistical analysis for the purpose of the study. Furthermore, a $37.0 \%$ response is considered sufficient considering that related studies have recorded a lower response rate (e.g., Cinquini \& Tenucci, 2010; Pitcher, 2015). Result from the analysis of respondents 'profile is presented in Tables 5(a)-(d).

Result shows that both male and female respondents participated in the study, although the number of male respondents is higher (Table 5(a)). From the result in Table 5(b), majority of the respondents have a second degree (70,57.4\%), while some others hold a doctorate degree $(14,11.5 \%)$. Furthermore, majority of the respondents are in the middle level management cadre (80,65.6\%), others belong to lower-level management $(24,19.7 \%)$ and top-level management (18, 14.8\%) respectively (Table 5(c)). In Table 5(d), almost than half of the respondents have up to 6 years of experience (less than 3 years $=8.2 \%+3-6$ years $=$ 
Table 4. (a) KMO and Bartlett's Test; (b) Communalities; (c) Total Variance Explained; (d) Component Matrixa.

(a)

\begin{tabular}{llc}
\hline Kaiser-Meyer-Olkin Measure of Sampling Adequacy. & 0.859 \\
\hline \multirow{2}{*}{ Bartlett's Test of Sphericity } & Approx. Chi-Square & 453.589 \\
& df & 10 \\
& Sig. & 0.000 \\
\hline
\end{tabular}

(b)

\begin{tabular}{ccc}
\hline & Initial & Extraction \\
\hline Profitability & 1.000 & 0.780 \\
Capacity utilization & 1.000 & 0.713 \\
Customer patronage & 1.000 & 0.738 \\
Product quality & 1.000 & 0.873 \\
Development of new products & 1.000 & 0.698 \\
\hline
\end{tabular}

Extraction Method: Principal Component Analysis.

(c)

\begin{tabular}{ccccccc}
\hline \multirow{2}{*}{ Component } & \multicolumn{3}{c}{ Initial Eigenvalues } & \multicolumn{2}{c}{ Extraction Sums of Squared Loadings } \\
& Total & \% of Variance Cumulative \% & Total & \% of Variance & Cumulative \% \\
1 & 3.801 & 76.022 & 76.022 & & & \\
2 & 0.495 & 9.898 & 85.920 & & & \\
3 & 0.321 & 6.425 & 92.344 & 3.801 & 76.022 & \\
4 & 0.234 & 4.671 & 97.015 & & & \\
5 & 0.149 & 2.985 & 100.000 & & & \\
\hline
\end{tabular}

Extraction Method: Principal Component Analysis.

(d)

\begin{tabular}{cc}
\hline & Component \\
Profitability & 1 \\
Capacity utilization & 0.883 \\
Customer patronage & 0.844 \\
Product quality & 0.859 \\
Development of new products & 0.934 \\
\hline
\end{tabular}

Extraction Method: Principal Component Analysis. ${ }^{a} 1$ components extracted.

Table 5. (a) Gender of Respondents; (b) Academic Qualification; (c) Cadre in Organization; (d) Length of Experience.

(a)

\begin{tabular}{cccccc}
\hline & & Frequency & Percent & Valid Percent & Cumulative Percent \\
\hline Valid & Male & 80 & 65.6 & 65.6 & 65.6 \\
& Female & 42 & 34.4 & 34.4 & 100.0 \\
& Total & 122 & 100.0 & 100.0 & \\
\hline
\end{tabular}


(b)

\begin{tabular}{cccccc}
\hline & & Frequency & Percent & Valid Percent & Cumulative Percent \\
\hline Valid & First Degree & 38 & 31.1 & 31.1 & 31.1 \\
& Second Degree & 70 & 57.4 & 57.4 & 88.5 \\
Third Degree & 14 & 11.5 & 11.5 & 100.0 \\
Total & 122 & 100.0 & 100.0 & \\
\hline
\end{tabular}

(c)

\begin{tabular}{cccccc}
\hline & Frequency & Percent & Valid Percent & Cumulative Percent \\
\hline Valid & Lower-level management & 24 & 19.7 & 19.7 & 19.7 \\
\cline { 2 - 4 } & & & & \\
Middle level management & 80 & 65.6 & 65.6 & 85.2 \\
Top Level management & 18 & 14.8 & 14.8 & 100.0 \\
Total & 122 & 100.0 & 100.0 & \\
\hline
\end{tabular}

(d)

\begin{tabular}{cccccc}
\hline & Frequency & Percent & Valid Percent & Cumulative Percent \\
\hline Valid & Less than 3 yrs & 10 & 8.2 & 8.2 & 8.2 \\
$3-6$ yrs & 50 & 41.0 & 41.0 & 49.2 \\
7 - 10 yrs & 38 & 31.1 & 31.1 & 80.3 \\
Above 10 yrs & 24 & 19.7 & 19.7 & 100.0 \\
Total & 122 & 100.0 & 100.0 & \\
\hline
\end{tabular}

$41.0 \%$, making a total of $49.2 \%), 31.1 \%$ have $7-10$ yrs experience, while the remaining has above 10 years of experience $(24,19.7 \%)$. Overall, the profile of respondents in Tables 5(a)-(d) suggests that respondents participating in the study are well experienced, well-educated and sufficiently qualified to participate in the study.

\subsection{Isomorphic Factors Affecting AI Application}

Result from the analysis of the Isomorphic factors affecting AI application is presented in Table 6 as follows.

Result in Table 6 generally shows that all items have a Mean score above 3.0 but below 4.0. This implies that the factors exert a moderate impact on the application of AI in American companies. However, a closer inspection of the table shows that the relatively high-ranking factors are Competitors' activities $(\mathrm{M}=3.57)$, Consultants/Professional bodies $(M=3.49)$, actions of Multinational organizations $(M=$ 3.48), and the need to satisfy customers $(M=3.48)$. These 4 items have a relatively high Mean. A thematic analysis of the high-ranking factor shows that the mimetic factors (i.e., competitors' activities and actions of multinational organizations) are the strongest factors driving the application of AI by the companies. The normative factor (i.e., recommendations of consultants/professional bodies/experts) also has appreciable influence on AI application. The only coercive factor that recorded a relatively high impact is the need to satisfy customers $(\mathrm{M}=3.48)$. On the other 
hand, other coercive factors such as government regulation $(M=3.20)$, company's shareholders $(M=3.20)$ and demands/pressure from Financial institutions/Fund Providers $(M=3.21)$ seem to exert relatively moderate pressure on organizations to apply AI. This may not be surprising, considering that AI is not currently mandated in the United States.

However, considering that the factors affecting AI application cut across the three categories of the isomorphic factors-coercive factors (customer), mimetic factors (Competitors' activities and actions of Multinational organizations) and normative factor (Recommendations of Consultants/Professional bodies) -it can be concluded that the theory of institutional isomorphism applied in the study is valid. In other words, isomorphic factors noticeably affect the adoption of AI by American companies.

Additional analysis using one sample t-test is presented in Table 7.

From the result in Table 7, each of the isomorphic factors has scores exceeding the test Mean of 3.0 as indicated under the column for Mean difference.

Table 6. One-Sample Statistics on Isomorphic factors affecting AI application.

\begin{tabular}{cccc}
\hline & Mean & Std. Deviation & $\begin{array}{c}\text { Std. Error } \\
\text { Mean }\end{array}$ \\
\hline Government regulations & 3.20 & 1.088 & 0.099 \\
Company's shareholders & 3.20 & 0.993 & 0.090 \\
Financial institutions/Fund Providers & 3.21 & 1.046 & 0.095 \\
Company's customers & 3.48 & 1.115 & 0.101 \\
Competitors' activities & 3.57 & 1.052 & 0.095 \\
Multinational organizations apply AI technologies & 3.48 & 0.996 & 0.091 \\
Recommendations of Consultants/Professional bodies & 3.49 & 1.054 & 0.095 \\
\hline
\end{tabular}

Table 7. One-Sample Test on Isomorphic factors affecting AI application.

\begin{tabular}{|c|c|c|c|c|c|c|}
\hline & \multicolumn{6}{|c|}{ Test Value $=3$} \\
\hline & \multirow[t]{2}{*}{$\mathbf{t}$} & \multirow[t]{2}{*}{ df } & \multirow{2}{*}{$\begin{array}{c}\text { Sig. } \\
\text { (2-tailed) }\end{array}$} & \multirow{2}{*}{$\begin{array}{c}\text { Mean } \\
\text { Difference }\end{array}$} & \multicolumn{2}{|c|}{$\begin{array}{c}95 \% \text { Confidence Interval } \\
\text { of the Difference }\end{array}$} \\
\hline & & & & & Lower & Upper \\
\hline Government regulations & 1.997 & 121 & 0.048 & 0.197 & 0.00 & 0.39 \\
\hline Company's shareholders & 2.188 & 121 & 0.031 & 0.197 & 0.02 & 0.37 \\
\hline $\begin{array}{l}\text { Financial institutions/ } \\
\text { Fund Providers }\end{array}$ & 2.250 & 121 & 0.026 & 0.213 & 0.03 & 0.40 \\
\hline Company's customers & 4.710 & 121 & 0.000 & 0.475 & 0.28 & 0.68 \\
\hline Competitors' activities & 6.026 & 121 & 0.000 & 0.574 & 0.39 & 0.76 \\
\hline $\begin{array}{c}\text { Multinational organizations } \\
\text { apply AI technologies }\end{array}$ & 5.318 & 119 & 0.000 & 0.483 & 0.30 & 0.66 \\
\hline $\begin{array}{c}\text { Recommendations of } \\
\text { Consultants/Professional } \\
\text { bodies }\end{array}$ & 5.152 & 121 & 0.000 & 0.492 & 0.30 & 0.68 \\
\hline
\end{tabular}


In essence, all values in this column are positive, implying that they exceed the test Mean of 3.0 on the 5-point measurement scale (equivalent to 60\%) Further, the difference in the Mean score between each of the isomorphic factors and the test Mean of 3.0 is statistically significant for all items. This provides further corroborative inferential evidence for the result in Table 6 that the isomorphic factors affect the application of AI in American companies. Taken together, the result in Table 6 and Table 7 leads to the conclusion that institutional isomorphic factors affect the application of AI by American companies. However, the level of influence exerted by the institutional factors is generally Moderate (research objective one).

\subsection{Impact of Isomorphic Factors on the Level of AI Application}

The result in Table 6 and Table 7 show the general influence of the institutional factors on AI application. To specifically ascertain the actual impact of each factor on AI application, regression analysis was employed. The result of the analysis is as presented in Tables 8(a)-(c) as follows.

In Table 8(a), the coefficient of determination ( $R$ square) is.463, meaning that the institutional factors jointly account for $46.3 \%$ of the level of AI application. The correlation coefficient $(\mathrm{R}=0.681)$ provides the omnibus correlation between the isomorphic factors and AI application of 68.1. The correlation coefficient and the coefficient of determination both provide corroborative evidence that institutional isomorphic factors affect the level of AI application by American companies. Furthermore, the Model ANOVA p value of 0.000 in Table 8(b) shows that the model is statistically significant at $5 \%(p=0.000<0.05)$. Result in Table 8(c) shows the specific impact of the isomorphic factors on AI application. A closer inspection of the result in Table 8(c) shows that the factors that are statistically significant are Government regulations (beta $=-0.152$ ), Financial institutions/Fund Providers (beta $=0.170$ ) and Company's customers (beta $=$ 0.406). However, going by the magnitude of the beta coefficient and level of statistical significance, the need to satisfy customers has the strongest positive impact on AI application with beta of 0.406 significant at $1 \%(p=0.000<0.05)$. This is followed by the pressure exerted by financial institutions/Fund Providers with a beta of 0.170 significant at $10 \%(p=0.085<0.10)$. Although the beta coefficient of Government regulations is statistically significant at $5 \%(p=0.040<0.05)$, the beta coefficient is negative (beta $=-0.152$ ), implying that government regulation has not motivated the adoption. This may not be surprising considering that AI is not currently regulated or mandated in the United States. To recap, although the results in Tables 8(a)-(c) establish that institutional isomorphic factors affect the level of AI application by American companies, the need to satisfy customers and pressure exerted by financial institutions/Fund Providers are strong drivers of AI application by American companies (research objective two).

\subsection{Impact of AI Application on Organizational Competitiveness}

Result from the analysis of the impact of AI application on organizational 
Table 8. (a) Model Summary; (b) ANOVA; ; (c) Coefficients ${ }^{\mathrm{a}}$.

(a)

\begin{tabular}{ccccc}
\hline Model & R & R Square & Adjusted R Square & Std. Error of the Estimate \\
\hline 1 & $0.681^{\mathrm{a}}$ & 0.463 & 0.430 & 0.63273 \\
\hline
\end{tabular}

aPredictors: (Constant), Recommendations of Consultants/Professional bodies, Company's shareholders, Government regulations, Competitors' activities, Company's customers, Financial institutions/Fund Providers, Multinational organizations apply AI technologies.

(b)

\begin{tabular}{ccccccc}
\hline & Model & Sum of Squares & df & Mean Square & F & Sig. \\
\hline 1 & Regression & 38.735 & 7 & 5.534 & & \\
& Residual & 44.839 & 112 & 0.400 & 13.822 & $0.000^{\mathrm{b}}$ \\
Total & 83.574 & 119 & & & \\
\hline
\end{tabular}

a Dependent Variable: Level of AI Application; 'bredictors: (Constant), Recommendations of Consultants/Professional bodies, Company's shareholders, Government regulations, Competitors' activities, Company's customers, Financial institutions/Fund Providers, Multinational organizations apply AI technologies.

(c)

\begin{tabular}{|c|c|c|c|c|c|c|}
\hline & \multirow[t]{2}{*}{ Model } & \multicolumn{2}{|c|}{$\begin{array}{l}\text { Unstandardized } \\
\text { Coefficients }\end{array}$} & \multirow{2}{*}{$\begin{array}{c}\begin{array}{c}\text { Standardized } \\
\text { Coefficients }\end{array} \\
\text { Beta }\end{array}$} & \multirow[t]{2}{*}{$\mathbf{t}$} & \multirow[t]{2}{*}{ Sig. } \\
\hline & & B & Std. Error & & & \\
\hline \multirow[t]{8}{*}{1} & (Constant) & 1.677 & 0.245 & & 6.853 & 0.000 \\
\hline & Government regulations & -0.152 & 0.073 & -0.198 & -2.080 & 0.040 \\
\hline & Company's shareholders & -0.108 & 0.109 & -0.128 & -0.990 & 0.324 \\
\hline & $\begin{array}{l}\text { Financial institutions/Fund } \\
\text { Providers }\end{array}$ & 0.170 & 0.098 & 0.212 & 1.740 & 0.085 \\
\hline & Company's customers & 0.406 & 0.084 & 0.537 & 4.857 & 0.000 \\
\hline & Competitors' activities & 0.025 & 0.093 & 0.031 & 0.268 & 0.790 \\
\hline & $\begin{array}{c}\text { Multinational organizations } \\
\text { apply AI technologies }\end{array}$ & 0.146 & 0.121 & 0.174 & 1.207 & 0.230 \\
\hline & $\begin{array}{c}\text { Recommendations of } \\
\text { Consultants/Professional bodies }\end{array}$ & 0.034 & 0.103 & 0.043 & 0.327 & 0.744 \\
\hline
\end{tabular}

aDependent Variable: Level of AI Application.

Table 9. (a) Model Summary; (b) ANOVA ${ }^{\mathrm{a}}$; (c) Coefficients ${ }^{\mathrm{a}}$.

(a)

\begin{tabular}{ccccc}
\hline Model & $\mathbf{R}$ & R Square & Adjusted R Square & Std. Error of the Estimate \\
\hline 1 & $0.700^{\mathrm{a}}$ & 0.490 & 0.485 & 0.53465 \\
\hline
\end{tabular}

apredictors: (Constant), Level of AI Application.

(b)

\begin{tabular}{ccccccc}
\hline & Model & Sum of Squares & df & Mean Square & F & Sig. \\
\hline 1 & Regression & 32.627 & 1 & 32.627 & & \\
Residual & 34.016 & 119 & 0.286 & 114.143 & $0.000^{\mathrm{b}}$ \\
Total & 66.643 & 120 & & & \\
\hline
\end{tabular}

a Dependent Variable: organizational competitiveness; 'Predictors: (Constant), Level of AI Application. 
(c)

\begin{tabular}{ccccccc}
\hline & & \multicolumn{2}{c}{ Unstandardized Coefficients } & $\begin{array}{c}\text { Standardized } \\
\text { Coefficients }\end{array}$ & & Sig. \\
\cline { 3 - 5 } & & B & Std. Error & Beta & & \\
\hline 1 & (Constant) & 1.686 & 0.212 & & 7.948 & 0.000 \\
& Level of AI Application & 0.630 & 0.059 & 0.700 & 10.684 & 0.000 \\
\hline
\end{tabular}

aDependent Variable: organizational competitiveness.

competitiveness is presented in Tables 9 (a)-(c) as follows.

In Table 9(a), the correlation coefficient (R) is.700, implying a strong relationship at $70.0 \%$ between AI application and organizational competitiveness. Furthermore, the coefficient of determination (R square) is 0.490 , meaning that the application of AI explains $49.0 \%$ of the variation in organizational competitiveness. Result in Table 9(b) establishes that the model is statistically significant as the ANOVA $p$ value is $0.000(p=0.000<0.05)$. In Table $9(\mathrm{c})$, the regressor coefficient of the independent variable (i.e., AI application) is also statistically significant. The standardized coefficient of the independent variable at 0.700 is the same as the correlation coefficient in Table 9(a). This provides corroborative evidence that the application of AI has a significant positive impact on organizational competitiveness (research objective three).

\section{Conclusion}

This study investigated the institutional factors affecting the application of AI by American companies. The objectives of the study were to: 1) determine the Institutional factors affecting AI; 2) evaluate the impact of institutional factors on application level of AI; and 3) assess the impact of AI on organizational competitiveness. Result shows that the relatively high-ranking institutional factors affecting AI application are Competitors' activities, Consultants/Professional bodies, actions of Multinational organizations, and the need to satisfy customers. These items have a relatively high Mean. Studies have shown that these factors affect technological innovation (e.g., Werner \& Gehrke, 2015; Zhou, Fu, \& Yang, 2016). A thematic analysis of the high-ranking factor shows that the mimetic factors (i.e., competitors' activities and actions of multinational organizations) are the strongest factors driving the application of AI by the companies. The normative factor (i.e., recommendations of consultants/professional bodies/experts) also has appreciable influence on AI application. The only coercive factor that recorded a relatively high impact is the need to satisfy customers. On the other hand, other coercive factors such as government regulation, company's shareholders and demands/pressure from financial institutions/Fund Providers seem to exert relatively moderate pressure on organizations to apply AI. This may not be surprising, considering that $\mathrm{AI}$ is not currently mandated in the United States (Stuart \& Norvig, 2016). In alignment with prior studies (e.g., Abdel Al \& McLellan, 2013), this result supports the conclusion that institutional isomor- 
phic factors affect the application of AI by American companies. However, the level of influence exerted by the institutional factors is generally Moderate (research objective one).

Result also shows that institutional factors jointly account for an appreciable level of AI application in American companies. This finding is in line with prior studies (e.g., Abdullah \& Said, 2015; Appelbaum, Kogan, \& Vasarhelyi, 2018). Whilst the factors significantly driving the application of AI are Government regulations (beta $=-0.152)$, Financial institutions/Fund Providers (beta $=0.170)$ and Company's customers (beta $=0.406$ ) - judging from the magnitude of the beta coefficient and level of statistical significance-the need to satisfy customers has the strongest positive impact on AI application. Studies have shown that the need to increase customer patronage has moved organizations to adopt innovation, and in recent time, customer-oriented organizations have increased their uptake of technological innovation (Baesens, Dejaeger, Lemahieu, \& Moges, 2013).

Studies have also shown that financiers and fund providers exert pressure on organizations to seek innovative ways of competing and improving performance in order to ensure such leveraged organizations continue as going concern and generate sufficient returns to repay their loan obligations (Bibi, Pangil, \& Johari, 2016). Result shows that government regulation and action does not currently motivate the adoption of AI. This is a grey area that government needs to look into urgently in order to drive the adoption of AI. Appropriate policies can be formulated to encourage companies to invest in $\mathrm{AI}$ in terms of tax incentives, tax reliefs for capital expenditure in acquiring technological facilities that drive AI, and encouraging the immigration of AI professionals and other IT experts to the U.S in order to further develop the ICT sector. Grants could also be made available, particularly for small and medium sized organizations, to scale up by investing in AI. Such investment in AI is expected to boost the American economy due to improved performance on account of extensively deploying AI.

Result suggests that the application of AI has a significant positive impact on organizational competitiveness (research objective three). This finding is consistent with other studies that AI improves organizational performance and sustains such performance into the foreseeable future (e.g., Boddy, 2012; Hamdan-Mansour, Al Shibi, Khalifeh, \& Hamdan-Mansour, 2020). This result also makes it compelling to encourage investment in AI given its significant positive impact on organizational competitiveness. However, it is important to note that such investment in AI which are usually capital intensive are long term in nature. The benefits of such investment may start accruing in the medium to long term. This is noteworthy in order to manage the expectation of management that the advantages may be realized in the short term-to discourage such short-term focus, decision-makers in organizations should realize that the early stage of investment in AI may be characterized by heavy cash outflow, but benefits should be realized in the long term. Such benefits of AI investment should 
not be judged strictly in terms of financial returns only. Benefits may be realized in non-financial terms in the way of improved efficiency, quick turnaround time, better customer satisfaction and improved quality of service delivery-these non-financial benefits may ultimately translate to financial gains through increased turnover and cost-savings.

This study contributes to knowledge by providing empirical evidence on the institutional factors affecting AI in American companies. This study is also one of the earliest empirical studies on the deployment of AI by listed companies in the U.S. the study therefore contributes to the burgeoning literature on AI. The study provides empirical evidence on the applicability of the theory of institutional isomorphism to the adoption of technological innovation. The study suffers from methodological limitations imposed by survey research design such as relying on respondents to provide information on internal organizational practices-responses may be trumped up, imposing response bias and Hawthorne effect. The small sample size also limits generalizability of results. To this end, future studies may use multiple-informer strategy rather than relying on a key informer per organization. A combination of data-gathering strategy such as the use of survey and in-depth interviews may also be applied in order to ensure well validated results. Future studies may also consider increasing the sample size to ensure sample representativeness.

\section{Conflicts of Interest}

The author declares no conflicts of interest regarding the publication of this paper.

\section{References}

Abdel Al, S. F., \& McLellan, J. D. (2013). Strategy and Management Accounting Practices Alignment and Its Effect on Organizational Performance. Journal of Accounting-Business \& Management, 20, 1-27.

Abdullah, N. H., \& Said, J. (2015). Enhancing the Governance of Government Linked Companies via Strategic Management Accounting Practices and Value Creation. Procedia Economics and Finance, 28, 222-229. https://doi.org/10.1016/S2212-5671(15)01103-X

Ahl, E. B. (1999). An Investigation of the Influence of Culture on Management Accounting. Master of Commerce Thesis, Department of Accounting and Finance, University of Wollongong. http://ro.uow.edu.au/theses/2266

Alreck, P. L., \& Settle, R. B. (1995). The Survey Research Handbook: Guidelines and Strategies for Conducting a Survey. IRWIN Professional Publishing.

Appelbaum, D. A., Kogan, A., \& Vasarhelyi, M. A. (2018). Analytical Procedures in External Auditing: A Comprehensive Literature Survey and Framework for External Audit Analytics. Journal of Accounting Literature, 40, 83-101.

https://doi.org/10.1016/j.acclit.2018.01.001

Appelbaum, D., Kogan, A., \& Vasarhelyi, M. A. (2017). Big Data and Analytics in the Modern Audit Engagement: Research Needs. Auditing: A Journal of Practice \& Theory, 36, 1-27. https://doi.org/10.2308/ajpt-51684 
Baesens, B., Dejaeger, K., Lemahieu, W., \& Moges, H. (2013). A Multidimensional Analysis of Data Quality for Credit Risk Management: New Insights and Challenges. Information \& Management, 50, 43-58. https://doi.org/10.1016/j.im.2012.10.001

Baron, I. S., Mustafa, \& Agustina, H. (2018). The Challenges of Recruitment and Selection Systems in Indonesia. Journal of Management and Marketing Review, 3, 185-192. https://doi.org/10.35609/jmmr.2018.3.4(2)

Bibi, P., Pangil, F., \& Johari, J. (2016). HRM Practices and Employees' Retention: The Perspective of Job Embeddedness Theory. Asian Journal of Multidisciplinary Study, 4, 41-47.

Boddy, D. (2012). Essentials of Management: A Concise Introduction. Pearson Education Limited.

Bondarouk, T., \& Brewster, C. (2016). Conceptualizing the Future of HRM and Technology Research. The International Journal of Human Resource Management, 27, 2652-2671. https://doi.org/10.1080/09585192.2016.1232296

Cinquini, L., \& Tenucci, A. (2010). Strategic Management Accounting and Business Strategy: A Loose Coupling? Journal of Accounting \& Organizational Change, 6, 228-259. https://doi.org/10.1108/18325911011048772

Cuganesan, S., Dunford, R., \& Palmer, I. (2012). Strategic Management Accounting and Strategy Practices within a Public-Sector Agency. Management Accounting Research, 23, 245-260. https://doi.org/10.1016/j.mar.2012.09.001

DiMaggio, P. J., \& Powell, W. W. (1983). The Iron Cage Revisited: Institutional Isomorphism and Collective Rationality in Organisational Fields. American Sociological Review, 48, 147-160. https://doi.org/10.2307/2095101

Drost, E. A. (2011). Validity and Reliability in Social Science Research Education. Research and Perspectives 38, 105-123.

Guido, G., Pichierri, M., Rizzo, C., Chieffi, V., \& Moschis, G. (2020). Information Processing by Elderly Consumers: A Five-Decade Review. Journal of Services Marketing, 35, 14-28. https://doi.org/10.1108/JSM-09-2019-0368

Hamdan-Mansour, A., Al Shibi, A. N., Khalifeh, A. H., \& Hamdan-Mansour, L. A. (2020). Health-Care Workers' Knowledge and Management Skills of Psychosocial and Mental Health Needs and Priorities of Individuals with COVID-19. Mental Health and Social Inclusion, 24, 135-144. https://doi.org/10.1108/MHSI-04-2020-0022

McRobert, C. J., Hill, J. C., Smale, T., Hay, E. M., \& Van der Windt, D. A. (2018). A Multi-Modal Recruitment Strategy Using Social Media and Internet-Mediated Methods to Recruit a Multidisciplinary, International Sample of Clinicians to an Online Research Study. PLoS ONE, 13, e0200184. https://doi.org/10.1371/journal.pone.0200184

Mohammadpoor, M., \& Torabi, F. (2019). Big Data Analytics in Oil and Gas Industry: An Emerging Trend. Petroleum, 6, 321-328. https://doi.org/10.1016/j.petlm.2018.11.001

Navickas, V., \& Gružauskas, V. (2016). Big Data Concept in the Food Supply Chain: Small Markets Case. Scientific Annals of Economics and Business, 63, 15-28. https://doi.org/10.1515/saeb-2016-0102

Oyewo, B., Ajibolade, S., \& Obazee, A. (2019). The Influence of Stakeholders on Management Accounting Practice. Journal of Sustainable Finance \& Investment, 9, 295-324. https://doi.org/10.1080/20430795.2019.1619336

Pitcher, G. S. (2015). Management Accounting in Support of the Strategic Management Process. CIMA Executive Summary Report, 11, 1-20.

https://www.cimaglobal.com/Research--Insight/Management-accounting-in-support-o f-the-strategic-management-process 
Rasmussen, T., \& Ulrich, D. (2015). Learning from Practice: How HR Analytics Avoids Being a Management Fad. Organizational Dynamics, 44, 236-242.

https://doi.org/10.1016/j.orgdyn.2015.05.008

Saunders, M., Lewis, P., \& Thornhill, A. (2007). Research Methods for Business Students (4th ed.). Pearson Education Limited.

Searle, R. H. (2006). New Technology: The Potential Impact of Surveillance Techniques in Recruitment Practices. Personnel Review, 35, 336-351. https://doi.org/10.1108/00483480610656720

Spenner, P., \& Freeman, K. (2012). To Keep Your Customers, Keep It Simple. Harvard Business Review, 90, 108-114.

Steenbruggen, J., Tranos, E., \& Nijkamp, P. (2015). Data from Mobile Phone Operators: A Tool for Smarter Cities? Telecommunications Policy, 39, 335-346.

https://doi.org/10.1016/j.telpol.2014.04.001

Stuart, R., \& Norvig, P. (2016). Artificial Intelligence: A Modern Approach (3rd ed.). Prentice Hall Press.

Sumbal, M. S., Tsui, E., \& See-to, E. W. K. (2017). Interrelationship between Big Data and Knowledge Management: An Exploratory Study in the Oil and Gas Sector. Journal of Knowledge Management, 21, 180-196. https://doi.org/10.1108/JKM-07-2016-0262

Werner, M., \& Gehrke, N. (2015). Multilevel Process Mining for Financial Audits. IEEE Transactions on Services Computing, 8, 820-832.

https://doi.org/10.1109/TSC.2015.2457907

Zhou, K., Fu, C., \& Yang, S. (2016). Big Data Driven Smart Energy Management: From Big Data to Big Insights. Renewable and Sustainable Energy Reviews, 56, 215-225.

https://doi.org/10.1016/j.rser.2015.11.050 


\section{Appendix 1: Frequency Distribution on Level of Application} of AI

The use of technologies that can master human intelligence in a short time.

\begin{tabular}{cccccc}
\hline & & Frequency & Percent & Valid Percent & Cumulative Percent \\
\hline Valid & 1 & 2 & 1.6 & 1.6 & 1.6 \\
& 2 & 20 & 16.4 & 16.4 & 18.0 \\
3 & 42 & 34.4 & 34.4 & 52.5 \\
4 & 40 & 32.8 & 32.8 & 85.2 \\
5 & 18 & 14.8 & 14.8 & 100.0 \\
& 122 & 100.0 & 100.0 & \\
\hline
\end{tabular}

The application of technologies that imitate human cognition.

\begin{tabular}{cccccc}
\hline & Frequency & Percent & Valid Percent & Cumulative Percent \\
\hline Valid & Not Applicable & 4 & 3.3 & 3.3 & 3.3 \\
& Low extent & 18 & 14.8 & 14.8 & 18.0 \\
& Moderate extent & 48 & 39.3 & 39.3 & 57.4 \\
High extent & 34 & 27.9 & 27.9 & 85.2 \\
Very High extent & 18 & 14.8 & 14.8 & 100.0 \\
Total & 122 & 100.0 & 100.0 & \\
\hline
\end{tabular}

The deployment of technologies that automate repetitive and time-consuming activities.

\begin{tabular}{cccccc}
\hline & Frequency & Percent & Valid Percent & Cumulative Percent \\
\hline Valid & Low extent & 10 & 8.2 & 8.2 & 8.2 \\
& Moderate extent & 40 & 32.8 & 32.8 & 41.0 \\
High extent & 38 & 31.1 & 31.1 & 72.1 \\
Very High extent & 34 & 27.9 & 27.9 & 100.0 \\
Total & 122 & 100.0 & 100.0 &
\end{tabular}

The use of technologies that analyze data in ways that human beings may sometimes not be able to.

\begin{tabular}{cccccc}
\hline & Frequency & Percent & Valid Percent & Cumulative Percent \\
\hline Valid & Low extent & 16 & 13.1 & 13.1 & 13.1 \\
& Moderate extent & 32 & 26.2 & 26.2 & 39.3 \\
High extent & 46 & 37.7 & 37.7 & 77.0 \\
Very High extent & 28 & 23.0 & 23.0 & 100.0 \\
Total & 122 & 100.0 & 100.0 & \\
\hline
\end{tabular}


The deployment of technologies that detect patterns and make predictions.

\begin{tabular}{cccccc}
\hline & Frequency & Percent & Valid Percent & Cumulative Percent \\
\hline Valid & Low extent & 14 & 11.5 & 11.5 & 11.5 \\
& Moderate extent & 34 & 27.9 & 27.9 & 39.3 \\
High extent & 40 & 32.8 & 32.8 & 72.1 \\
Very High extent & 34 & 27.9 & 27.9 & 100.0 \\
Total & 122 & 100.0 & 100.0 & \\
\hline
\end{tabular}

The application of technologies that simulate human consciousness.

\begin{tabular}{cccccc}
\hline & Frequency & Percent & Valid Percent & Cumulative Percent \\
\hline Valid & Not Applicable & 10 & 8.2 & 8.2 & 8.2 \\
& Low extent & 30 & 24.6 & 24.6 & 32.8 \\
Moderate extent & 42 & 34.4 & 34.4 & 67.2 \\
High extent & 24 & 19.7 & 19.7 & 86.9 \\
Very High extent & 16 & 13.1 & 13.1 & 100.0 \\
Total & 122 & 100.0 & 100.0 & \\
\hline
\end{tabular}

\section{Appendix 2: Frequency Distribution on Institutional Factors Influencing Deployment of Artificial Intelligence Technologies}

Government regulations.

\begin{tabular}{cccccc}
\hline & Frequency & Percent & Valid Percent & Cumulative Percent \\
\hline Valid & Very Low & 8 & 6.6 & 6.6 & 6.6 \\
& Low & 22 & 18.0 & 18.0 & 24.6 \\
Moderate & 46 & 37.7 & 37.7 & 62.3 \\
High & 30 & 24.6 & 24.6 & 86.9 \\
Very High & 16 & 13.1 & 13.1 & 100.0 \\
Total & 122 & 100.0 & 100.0 &
\end{tabular}

Company's shareholders.

\begin{tabular}{cccccc}
\hline \multirow{3}{*}{ Valid } & Frequency & Percent & Valid Percent & Cumulative Percent \\
& Very Low & 4 & 3.3 & 3.3 & 3.3 \\
Low & 22 & 18.0 & 18.0 & 21.3 \\
Moderate & 58 & 47.5 & 47.5 & 68.9 \\
High & 22 & 18.0 & 18.0 & 86.9 \\
Very High & 16 & 13.1 & 13.1 & 100.0 \\
Total & 122 & 100.0 & 100.0 & \\
\hline
\end{tabular}


Financial institutions/Fund Providers.

\begin{tabular}{cccccc}
\hline & Frequency & Percent & Valid Percent & Cumulative Percent \\
\hline Valid & Very Low & 8 & 6.6 & 6.6 & 6.6 \\
Low & 18 & 14.8 & 14.8 & 21.3 \\
Moderate & 50 & 41.0 & 41.0 & 62.3 \\
High & 32 & 26.2 & 26.2 & 88.5 \\
Very High & 14 & 11.5 & 11.5 & 100.0 \\
Total & 122 & 100.0 & 100.0 & \\
\hline
\end{tabular}

Company's customers.

\begin{tabular}{cccccc}
\hline & Frequency & Percent & Valid Percent & Cumulative Percent \\
\hline Valid & Very Low & 4 & 3.3 & 3.3 & 3.3 \\
& Low & 18 & 14.8 & 14.8 & 18.0 \\
Moderate & 46 & 37.7 & 37.7 & 55.7 \\
High & 24 & 19.7 & 19.7 & 75.4 \\
Very High & 30 & 24.6 & 24.6 & 100.0 \\
Total & 122 & 100.0 & 100.0 & \\
\hline
\end{tabular}

Competitors' activities.

\begin{tabular}{cccccc}
\hline & Frequency & Percent & Valid Percent & Cumulative Percent \\
\hline Valid & Very Low & 6 & 4.9 & 4.9 & 4.9 \\
& Low & 8 & 6.6 & 6.6 & 11.5 \\
Moderate & 44 & 36.1 & 36.1 & 47.5 \\
High & 38 & 31.1 & 31.1 & 78.7 \\
Very High & 26 & 21.3 & 21.3 & 100.0 \\
Total & 122 & 100.0 & 100.0 & \\
\hline
\end{tabular}

Multinational organizations apply AI technologies.

\begin{tabular}{cccccc}
\hline & & Frequency & Percent & Valid Percent & Cumulative Percent \\
\hline Valid & Very Low & 6 & 4.9 & 5.0 & 5.0 \\
& Low & 10 & 8.2 & 8.3 & 13.3 \\
& Moderate & 40 & 32.8 & 33.3 & 46.7 \\
& High & 48 & 39.3 & 40.0 & 86.7 \\
& Very High & 16 & 13.1 & 13.3 & 100.0 \\
& Total & 120 & 98.4 & 100.0 & \\
& Total & 2 & 1.6 & & \\
\hline
\end{tabular}


Recommendations of Consultants/Professional bodies.

\begin{tabular}{cccccc}
\hline & Frequency & Percent & Valid Percent & Cumulative Percent \\
\hline Valid & Very Low & 6 & 4.9 & 4.9 & 4.9 \\
& Low & 10 & 8.2 & 8.2 & 13.1 \\
Moderate & 48 & 39.3 & 39.3 & 52.5 \\
High & 34 & 27.9 & 27.9 & 80.3 \\
Very High & 24 & 19.7 & 19.7 & 100.0 \\
Total & 122 & 100.0 & 100.0 & \\
\hline
\end{tabular}

\section{Appendix 3: Questionnaire Sample}

\section{DETERMINANTS AND IMPACT OF ARTIFICIAL INTELLIGENCE (AI) ON THE COMPETITIVENESS OF AMERICAN COMPANIES}

The purpose of this questionnaire is to obtain your opinion on the determinants and impact of the deployment of artificial intelligence (AI) technologies on the competitiveness of American companies.

Please be assured that the information provided will be treated with confidentiality, as the purpose of this study is for academic purpose.

Kindly provide answers as honestly as you can. Thank you for deciding to participate in this survey.

Yours Faithfully,

Chinwe Researcher

\section{SECTION A: DATA ON RESPONDENT}

\section{Gender: $\quad$ Male ( ) Female ( )}

Academic Qualification: First Degree（） Second Degree（ ）

Third Degree ( )

Cadre in Organization: Lower level management $(\quad$ )

Middle level management ( )

Top Level management ( )

Length of Experience: Less than 3 yrs ( ) 3 - 6 yrs ( )

$7-10 \mathrm{yrs}() \quad$ Above $10 \mathrm{yrs}()$

\footnotetext{
B: APPLICATION OF ARTIFICIAL INTELLIGENCE

Please rate the extent to which the following artificial intelligence technologies are deployed in your organization

KEY: $1=$ Not Applicable $\quad 2=$ Low extent $\quad 3=$ Moderate extent $\quad 4=$ High extent $\quad 5=$ Very High extent
}

1 The use of technologies that can master human intelligence in a short time

2 The application of technologies that imitate human cognition

3 The deployment of technologies that automate repetitive and time-consuming activities

4 The use of technologies that analyze data in ways that human beings may sometimes not be able to.

5 The deployment of technologies that detect patterns and make predictions

6 The application of technologies that simulate human consciousness 


\section{C: AREAS OF APPLICATION OF ARTIFICIAL INTELLIGENCE}

Please rate the extent to which technologies that simulate human consciousness (i.e., artificial intelligence) are applied in the following areas in your organization

KEY: 1 = Not Applicable

$$
2=\text { Low extent } \quad 3=\text { Moderate extent } \quad 4=\text { High extent } \quad 5=\text { Very High extent }
$$

\begin{tabular}{|c|c|c|c|c|c|c|}
\hline & & 1 & 2 & 3 & 4 & 5 \\
\hline 1 & Human Resource Management & & & & & \\
\hline 2 & Production & & & & & \\
\hline 3 & Accounts/Finance & & & & & \\
\hline 4 & Internal control/Internal Audit & & & & & \\
\hline 5 & Procurement & & & & & \\
\hline 6 & Marketing and Sales & & & & & \\
\hline 7 & Customer Service & & & & & \\
\hline
\end{tabular}

D: INSTITUTIONAL FACTORS INFLUENCING DEPLOYMENT OF ARTIFICIAL INTELLIGENCE TECHNOLOGIES

Please rate extent to which the following factors influence the decision to deploy artificial intelligence (i.e., technologies that simulate human consciousness) in your organization

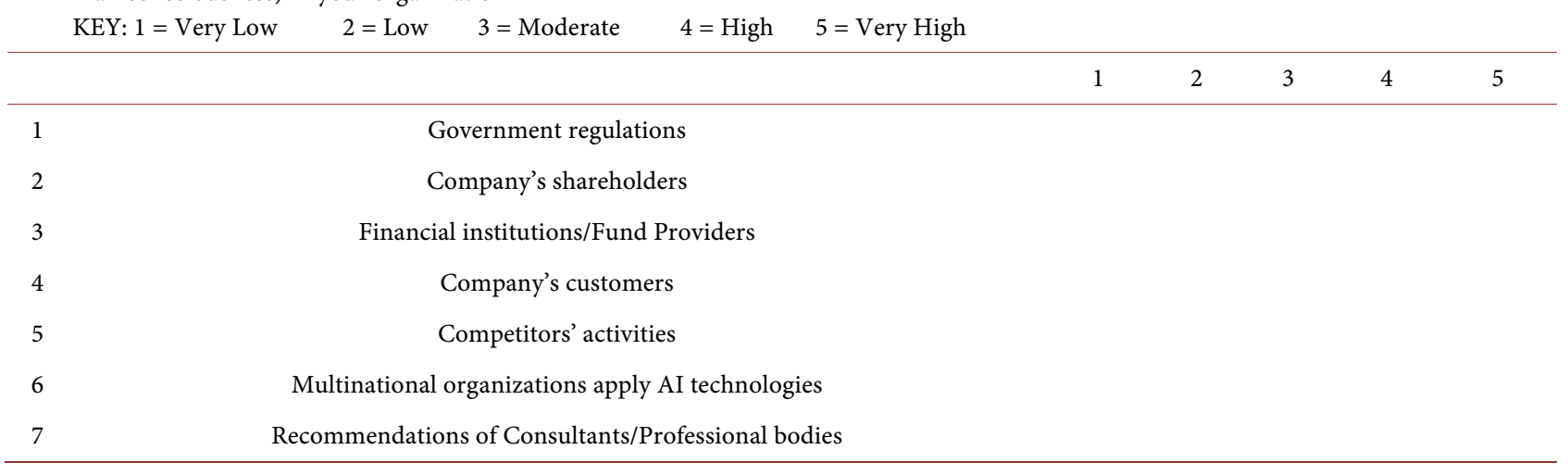

\section{E: INNOVATION ATTRIBUTES AFFECTING THE APPLICATION OF ARTIFICIAL INTELLIGENCE (AI)}

Please rate the extent to which the following factors influence the decision to deploy artificial intelligence (i.e., technologies that simulate human consciousness) in your organization

\begin{tabular}{lcccccc} 
KEY: Not at all $=1$ & Little extent $=2$ & Moderate extent $=3$ & Great Extent $=4$ & Very Great Extent $=5$ & \\
\hline S/N & ITEM & 1 & 2 & 3 & 4 & 5 \\
\hline
\end{tabular}

1 AI deployment is influenced by the consideration that it enhances operational efficiency

2 Decision to adopt AI is influenced by the need to save cost and time pertaining to repetitive tasks performed by employees in the organization

3 Decision to adopt $\mathrm{AI}$ is informed by the value placed on continuous improvement and innovativeness

4 Adoption of $\mathrm{AI}$ is affected by the experience of new ideas implemented in the past

5 The difficulty of understanding AI affects the decision to adopt

6 The challenges of implementing AI affect adoption

7 The awareness that AI technologies can be test run/run on a trial basis affects adoption

The consideration that AI technologies can be implemented in phases affects adoption decision

Visible result of AI implementation by other organizations affects our company's decision to adopt

10 Discussions on the outcome of AI implementation by professionals, consultants and other organizations influence the decision to adopt 
F: COMPETITIVE ADVANTAGE

Please rate how the performance of your company compares with competitors over the past 3 years in the following areas:

KEY: Far Below Average $=1 \quad$ Below Average $=2$

Average $=3$

Above Average $=4$

Far Above average $=5$

$\begin{array}{llllll}1 & 2 & 3 & 4 & 5\end{array}$

1 Profitability

2 Capacity utilization

3 Customer patronage

4 Product quality

5 Development of new products 